\title{
Trends in burden of chronic obstructive pulmonary disease in Iran, 1995-2015: findings from the global burden of disease study
}

Seyed Yaser Hashemi ${ }^{1}$, Victoria Momenabadi ${ }^{2}$, Ahmad Faramarzi ${ }^{3^{*}}$ and Amin Kiani ${ }^{4^{*}}$

\begin{abstract}
Background: Chronic obstructive pulmonary disease (COPD) is a heterogeneous disorder that progresses over time, and currently it is the fourth leading cause of death across the globe. The World Health Organization (WHO) predicts that the disease will become the third leading cause of death by 2030. The present study aimed to assess the burden trends of COPD in Iran by estimating the disability-adjusted life years (DALYs) from 1995 to 2015.

Methods: Data were retrospectively collected as the Global Burden of Disease (GBD) from 1995 to 2015 and published by the Institute for Health Metrics and Evaluation. We applied DALYs, incidence and prevalence rate to report the burden of COPD in Iran. To assess the statistical significance according to trend, the CochranArmitage test was applied. Additionally, the t-test was used to analyze the DALYs number by gender and Onaway ANOVA by age groups at a significance level set at $P<0.05$.

Results: From 1995 to 2015, there were approximately 1.1 million DALYs attributable to COPD in Iran. In both genders and at all ages, the number of DALYs increased significantly from 176,224 in 1995 to 253,618 in 2015. The incidence and prevalence rate were 76.65 and 1491.37 per 100,000 population, respectively in both genders in 2015 in Iran. It is noticeable that the number of deaths during the study years, 1995 to 2015, was 39,064 . This study showed that the COPD burden was significantly different by age groups and gender.

Conclusions: COPD is still a public health problem in Iran and has an increasing trend. The majority of DALYS were due to the years of life lost as a result of premature death (YLLS), indicating that prevention and early detection, especially in the age groups of 15 to 70 years, should be considered.
\end{abstract}

Keywords: COPD, DALY, Prevalence, Incidence, Mortality

\footnotetext{
*Correspondence: ahmadfaramarzi97@gmail.com; amin.k2010@yahoo.com

${ }^{3}$ Department of Health Management and Economics, School of Public

Health, Urmia University of Medical Sciences, Urmia, Iran

${ }^{4}$ School of Public Health, Fasa University of Medical Sciences, Fasa, Iran

Full list of author information is available at the end of the article

(c) The Author(s). 2020 Open Access This article is licensed under a Creative Commons Attribution 4.0 International License, which permits use, sharing, adaptation, distribution and reproduction in any medium or format, as long as you give appropriate credit to the original author(s) and the source, provide a link to the Creative Commons licence, and indicate if changes were made. The images or other third party material in this article are included in the article's Creative Commons licence, unless indicated otherwise in a credit line to the material. If material is not included in the article's Creative Commons licence and your intended use is not permitted by statutory regulation or exceeds the permitted use, you will need to obtain permission directly from the copyright holder. To view a copy of this licence, visit http://creativecommons.org/licenses/by/4.0/ The Creative Commons Public Domain Dedication waiver (http://creativecommons.org/publicdomain/zero/1.0/) applies to the data made available in this article, unless otherwise stated in a credit line to the data.
} 


\section{Background}

Chronic obstructive pulmonary disease (COPD) is a heterogeneous disorder that progresses over time, and characterized by airflow limitation that is not fully reversible $[1,2]$. Recently, COPD has grown dramatically, making it the fourth leading cause of death across the globe. In this regard, the World Health Organization (WHO) predicts that the disease will become the third leading cause of death by 2030 [3]. The prevalence of COPD is increasing due to urbanization, industrial pollution, tanneries and biomass fuel burning inside homes, especially in Asian and African countries [4]. A study calculated a mean prevalence of $13.4 \%$ for COPD in Africa, ranging from 9.4 to $22.1 \%$ [5]. However, in Asia, its prevalence was reported $13.5 \%$ with a range of 3 to $22.2 \%$ [6].

Furthermore, COPD is a common reason for hospital admission in many countries, playing a crucial role in imposing health care costs [7]. A systematic review demonstrated that the annual hospitalization cost per patient for the COPD in the United States was \$6852, and in Iran and China, it was estimated as $\$ 865$ and $\$ 1477$, respectively [8]. Another study reported a health care expenditure of $£ 781$ to $£ 1639$ in the United Kingdom, per patient per year [9].

The Global Burden of Disease (GBD) study provides estimates of a burden of disease, an approach summarizing the effects of morbidity and premature mortality in a special population, in different countries and regions $[10,11]$. To estimate disease trends, the burden of diseases is employed in different indicators such as incidence, prevalence, duration and mortality [12, 13]. Among the specified indexes, we emphasized on disability-adjusted life years (DALYs) to measure the burden of COPD in Iran.

Although, COPD has imposed an extensive burden on the health, life expectancy, and well-being of the population in low and middle-income countries like Iran. Based on the GBD study, there were 40,141 incidence cases of COPD in 1995 in Iran, and the incidence rate was 60, 587 in 2015 [14]. Most studies into the burden of COPD have been conducted in developed countries, and there is no study in Iran. Therefore, the main purpose of this study was to assess the burden trends of COPD in Iran by estimating the years of life lost due to premature death (YLLs) and the years lived with disability (YLDs) in patients with COPD. Moreover, indicators such as number of deaths, prevalence, incidence, and mortality rate were evaluated.

\section{Materials and methods Data collection}

The data of the number of DALYs for COPD were derived from the results of the GBD study. The data were extracted during 1995 to 2015 . The GBD study was published by the Institute for Health Metrics and Evaluation (IHME). The first report of the GBD study was published in 1990, and it has been published annually to the present. The GBD study has recruited a consortium of more than 3600 researchers in more than 145 countries to collect and analyze data. The initial data on the GBD study are premature death and disability from more than 350 diseases and injuries in 195 countries by age and sex. The GBD study applies different sources to assess the outcomes of health loss. These sources are the death registration systems, vital registration, verbal autopsy, mortality surveillance and others. A complete description of the data, statistical modeling, and metrics has been specified in the references $[15,16]$.

\section{Data analysis}

The current research is a secondary analysis of the GBD study results. To evaluate the trend of COPD burden in Iran, we used mortality and morbidity indices. The number of deaths, incidence and prevalence rate, YLLs, YLDs, and DALYs are reported for both sexes and all age groups from 1995 to 2015. In the GBD study, the results were reported based on different age grouping; we applied the method proposed by the WHO and other studies. These groups include under 5 years, 5-14 years, $15-49$ years, $50-69$ years, and over 70 years.

In this study, we highlighted DALYs and their component to measure the burden of COPD in Iran DALY is a tool developed by the World Health Organization (WHO) to measure, compare, and analyze the burden of various diseases [11]. This metric combines the years of life lost due to premature death (YLLs) and the time lived in states of less than optimal health, loosely referred to as disability (YLDs), for a special cause in a given year. A DALY is equal to the loss of 1 year of "healthy" life from the combined impacts of mortality and disability. In fact, DALY for the particular sex and age is taken by summing YLLs and YLDs in a given year $[17,18]$. In the GBD study, YLLs are considered a measure of cause-specific premature mortality. Therefore, for a given cause, age, and sex, this metric is equal to the death number multiplied by the standard life expectancy [19]. YLDs were derived from the multiplication of the incidence number for a specific reason by the duration of disability and a weight factor [20].

To more accurately explain the burden of COPD in Iran, we performed the following steps.

First, given to different classifications on COPD, we used the 10th version of the International Classification of Diseases (ICD). These diseases fall into the category of chronic respiratory diseases, and it includes emphysema means an anatomical condition characterized by destruction and enlargement of the lung alveoli, chronic bronchitis, which is a clinical condition with chronic 
cough and phlegm, and small airways disease, a condition in which small bronchioles are narrowed. Then, number of deaths, prevalence and incidence rate, DALYs number, YLLs and YLDs were reported to obtain a description of COPD. Second, the trends in the burden of COPD were investigated. We assessed the trends by gender and age groups. To assess statistical significance according to trend, the Cochran-Armitage test was applied. Additionally, the t-test was used for analysis, since the mean of variables was compared between the two groups of males and females. Furthermore, one-way ANOVA analysis was applied to assess the burden according to age groups. The significance level was set at 0.05 . We used the Stata version 13 and Microsoft Office Excel 2013 programs to perform our analysis.

\section{Results}

In the following, we report noticeable findings from the GBD attributed to the burden of COPD in Iran from 1995 to 2015. The number of DALYs, YLLs, YLDs are described. Moreover, death number, incidence, and prevalence rate are reported.

\section{Death number, incidence and prevalence rate}

In Iran, there were 39,064 deaths in both genders from 1995 to 2015 due to COPD. The number of deaths was 4899 in 1995 and 10,514 in 2015 for both sexes. The incidence rate for both genders was increased from 66.32 per 100,000 population in 1995 to 76.65 in 2015. The prevalence rate increased from 1247.87 in 1995 to 1491.37 per 100,000 population in 2015 in both genders. Furthermore, the results of this study indicated that number of deaths, incidence, and prevalence rate were significantly higher in males than in females ( $p$-value< $0.05)$. Table 1 shows the number of deaths, incidence and prevalence rate for COPD according to years and age groups.

\section{DALYs, YLLs and YLDs}

Table 2 presents the number of DALYs and deaths due to COPD in Iran from 1995 to 2015 based on age groups and sex. From 1995 to 2015, it was estimated that there were 1,059,491 DALYs of COPD for all ages in Iran, of
Table 2 The death and DALYs number of COPD in different age groups in Iran from 1995 to 2015

\begin{tabular}{lllllllll}
\hline & \multicolumn{3}{l}{ DALYs number } & & & \multicolumn{3}{c}{ Death number } \\
\cline { 2 - 3 } Age groups & Female & Male & Total & & Female & Male & Total \\
\hline Under $\mathbf{5}$ & 41,161 & 43,947 & 85,108 & & 468 & 502 & 970 \\
$\mathbf{5 - 1 4}$ years & 13,260 & 13,149 & 26,409 & & 61 & 72 & 133 \\
$\mathbf{1 5 - 4 9}$ years & 115,857 & 188,500 & 304,357 & & 1272 & 2580 & 3852 \\
$\mathbf{5 0 - 6 9}$ years & 126,499 & 226,095 & 352,594 & & 3896 & 7234 & 11,130 \\
> 70 years & 110,303 & 180,720 & 291,023 & & 8932 & 14,047 & 22,979 \\
All ages & 407,082 & 652,409 & $1,059,491$ & 14,630 & 24,434 & 39,064 \\
\hline
\end{tabular}

which 652,409 DALYs occurred for males and 407,082 DALYs for females. The number of deaths was calculated 39,064 for all ages. The age group 50-69 years with 352,594 years had the highest DALYs, followed by the age group $15-49$ years with 304,357 years.

The number of DALYs due to COPD in Iran for all ages was 176,224 in 1995 and, it was increased to 253, 618 in 2015. > Throughout the years, the number of DALYs on COPD was associated with YLLs to YLDs. At all ages and in both genders, the YLLs were 137,461 in 1995 and 203,558 in 2015. Whereas, the YLDs were 38, 761 in 1995 and 50,058 in 2015 (Table 3). The results also revealed that the burden of COPD in Iran had a significant trend from 1995 to 2015.

Our findings demonstrated the burden of COPD was higher in males than in females. The rate of YLLs was 265 and 189 per 100,000 population for males and females, respectively. Nevertheless, the rate was increased to 345 per 100,000 population in males in 2015 and was decreased to 168 in females. Figure 1 shows the rate of YLLs and YLDs per 100,000 population on COPD by gender.

This study indicates that the maximum of the DALYs number between 1995 and 2015 was associated with the age groups of 50-69, 15-49 and $>70$ years. Figure 2 illustrates the DALYs number across different age groups. In 2015, the DALYs number on the age group 50-69 years for both genders was 103.1 thousand, 74.8 thousand for the group $>70$, and 67.7 thousand in the age group 15-49 years. As Fig. 2 shows, the group under 5-

Table 1 The number of deaths, incidence and prevalence rate of COPD in Iran from 1995 to 2015

\begin{tabular}{|c|c|c|c|c|c|c|c|c|c|c|c|c|}
\hline \multirow[t]{2}{*}{ Years } & \multicolumn{4}{|c|}{ Death number } & \multicolumn{4}{|c|}{ Incidence per 100,000} & \multicolumn{4}{|c|}{ Prevalence per 100,000 } \\
\hline & Male & Female & Both & $P$ value & Male & Female & Both & $P$ value & Male & Female & Both & $P$ value \\
\hline 1995 & 2977 & 1922 & 4899 & $0.009^{*}$ & 77.83 & 54.47 & 66.32 & $0.004^{*}$ & 1403.26 & 1087.96 & 1247.87 & $0.008^{*}$ \\
\hline 2000 & 3481 & 2209 & 5690 & & 79.89 & 52.24 & 66.25 & & 1486.94 & 1090.93 & 1291.6 & \\
\hline 2005 & 5058 & 3149 & 8208 & & 83.25 & 51.3 & 67.61 & & 1578.72 & 1102.31 & 1345.45 & \\
\hline 2010 & 5937 & 3816 & 9753 & & 90.18 & 53.97 & 72.28 & & 1702.5 & 1144.46 & 1426.76 & \\
\hline 2015 & 6981 & 3532 & 10,514 & & 96.33 & 56.69 & 76.65 & & 1785.17 & 1193.12 & 1491.37 & \\
\hline
\end{tabular}

*The $P$-value indicates statistical significance between male and female groups for death number, crude incidence, and prevalence rate 
Table 3 YLLs and YLDs of COPD in different age groups in Iran from 1995 to 2015

\begin{tabular}{|c|c|c|c|c|c|c|c|c|c|c|}
\hline \multirow[b]{2}{*}{ age } & \multirow[b]{2}{*}{ year } & \multicolumn{2}{|l|}{ YLLs } & \multicolumn{2}{|l|}{ YLDs } & \multicolumn{3}{|l|}{ DALYS } & \multirow{2}{*}{$\begin{array}{l}\text { Cochran- } \\
\text { Armitage test }\end{array}$} & \multirow{2}{*}{$\begin{array}{l}\text { Onaway } \\
\text { ANOVA }\end{array}$} \\
\hline & & Female & Male & Female & Male & Female & Male & Both & & \\
\hline Under 5 & 1995 & 17,148 & 16,553 & 325 & 265 & 17,474 & 16,819 & 34,293 & $Z=2$ & $F=19$ \\
\hline 5-14 years & 1995 & 1602 & 1784 & 2771 & 2317 & 4374 & 4101 & 8476 & & \\
\hline $15-49$ years & 1995 & 11,464 & 19,259 & 9342 & 10,202 & 20,807 & 29,462 & 50,270 & & \\
\hline $50-69$ years & 1995 & 15,367 & 26,653 & 3853 & 5422 & 19,221 & 32,076 & 51,298 & & \\
\hline$>70$ years & 1995 & 10,705 & 16,921 & 1796 & 2462 & 12,502 & 19,383 & 31,885 & & \\
\hline All ages & 1995 & 56,289 & 81,172 & 18,090 & 20,671 & 74,380 & 101,843 & 176,224 & & \\
\hline Under 5 & 2000 & 11,563 & 13,516 & 213 & 183 & 11,776 & 13,700 & 25,476 & & \\
\hline 5-14 years & 2000 & 1245 & 1474 & 2222 & 1994 & 3467 & 3469 & 6936 & & \\
\hline $15-49$ years & 2000 & 12,677 & 23,403 & 10,042 & 11,741 & 22,719 & 35,145 & 57,864 & & \\
\hline 50-69 years & 2000 & 16,549 & 28,074 & 3911 & 5637 & 20,460 & 33,712 & 54,173 & & \\
\hline$>70$ years & 2000 & 13,851 & 21,512 & 2132 & 2977 & 15,984 & 24,489 & 40,473 & & \\
\hline All ages & 2000 & 55,886 & 87,982 & 18,521 & 22,533 & 74,407 & 110,516 & 184,924 & & \\
\hline Under 5 & 2005 & 6221 & 7634 & 151 & 138 & 6373 & 7772 & 14,145 & & \\
\hline 5-14 years & 2005 & 869 & 1103 & 1427 & 1318 & 2297 & 2421 & 4719 & & \\
\hline $15-49$ years & 2005 & 12,850 & 25,606 & 10,358 & 12,820 & 23,209 & 38,427 & 61,637 & & \\
\hline 50-69 years & 2005 & 19,916 & 34,580 & 4143 & 6115 & 24,059 & 40,696 & 64,755 & & \\
\hline$>70$ years & 2005 & 23,377 & 37,068 & 2528 & 3798 & 25,905 & 40,867 & 66,773 & & \\
\hline All ages & 2005 & 63,235 & 105,994 & 18,609 & 24,191 & 81,844 & 130,186 & 212,031 & & \\
\hline Under 5 & 2010 & 2972 & 2950 & 136 & 130 & 3109 & 3081 & 6191 & & \\
\hline 5-14 years & 2010 & 552 & 645 & 1047 & 1020 & 1599 & 1666 & 3265 & & \\
\hline $15-49$ years & 2010 & 13,832 & 28,581 & 10,796 & 13,648 & 24,629 & 42,229 & 66,858 & & \\
\hline 50-69 years & 2010 & 23,762 & 43,469 & 5003 & 7007 & 28,765 & 50,476 & 79,242 & & \\
\hline$>70$ years & 2010 & 27,823 & 41,995 & 2974 & 4340 & 30,798 & 46,336 & 77,134 & & \\
\hline All ages & 2010 & 68,943 & 117,642 & 19,959 & 26,148 & 88,902 & 143,790 & 232,693 & & \\
\hline Under 5 & 2015 & 2291 & 2442 & 137 & 130 & 2428 & 2573 & 5002 & & \\
\hline $5-14$ years & 2015 & 441 & 505 & 1080 & 938 & 1521 & 1489 & 3011 & & \\
\hline $15-49$ years & 2015 & 13,297 & 29,139 & 11,194 & 14,094 & 24,492 & 43,234 & 67,726 & & \\
\hline 50-69 years & 2015 & 27,742 & 60,296 & 6248 & 8835 & 33,991 & 69,132 & 103,123 & & \\
\hline$>70$ years & 2015 & 22,162 & 45,239 & 2950 & 4402 & 25,113 & 49,642 & 74,755 & & \\
\hline All ages & 2015 & 65,934 & 137,624 & 21,611 & 28,447 & 87,546 & 166,071 & 253,618 & & \\
\hline
\end{tabular}

The Cochran-Armitage test indicates that the DALYs number of COPD has a significant trend from 1995 to 2015. The Onaway ANOVA shows a significant difference in the number of DALYs between age groups

year has a diminishing trend in the DALYs number from 1995 to 2015.

\section{Discussion}

There were various indicators applied to study the burden of diseases such as number of deaths, prevalence and incidence rate, DALY, YLL, and YLD. In this study, we investigated the burden of COPD according to the results of the GBD study in Iran and set an applicable pattern for COPD burden. Approximately 10,514 deaths and 253.6 thousand DALYs of COPD were estimated, and the incidence and prevalence rate were 76.6 and 1491 per 100,000 population, respectively, in both genders in Iran in 2015. Interestingly, the number of deaths during the study years, 1995 to 2015, was 39.1 thousand, and the number of DALYs was approximately 1.1 million. These estimates indicate that the number of DALYs due to COPD in Iran accounts for $1.2 \%$ of total DALYs in 2015, and the number of COPD deaths in Iran includes almost $2.8 \%$ of all deaths. Moreover, this study demonstrates that the COPD burden in Iran is more than that of some countries. For example, the burden of COPD in African countries was responsible for $0.3 \%$ of all DALYs, and $1.1 \%$ of all DALYs in high-mortality countries in American countries. However, there are many countries with a higher burden of COPD 


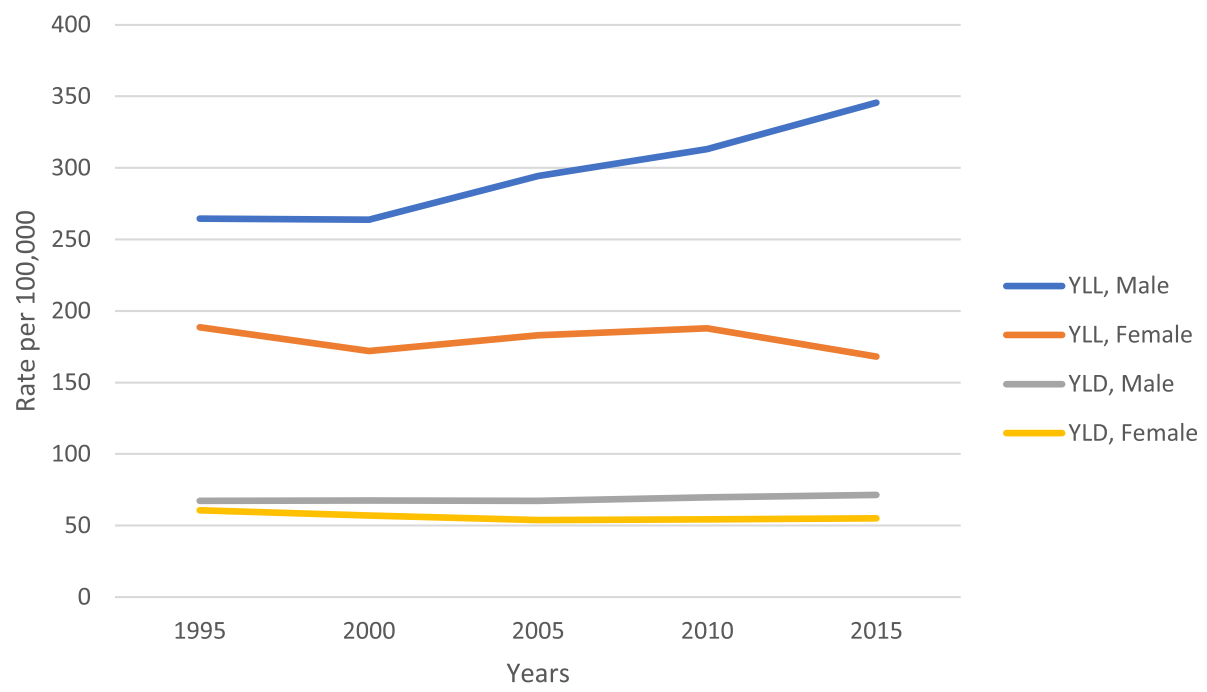

Fig. 1 The rate of DALY per 100,000 of COPD by sex in Iran from 1995 to 2015

compared to Iran. The number of DALYs due to COPD in South-East Asia consists of 2.3 and $1.9 \%$ of all DALYs in countries with low and high mortality, respectively. Furthermore, COPD causes approximately $2 \%$ of the entire global burden of diseases [21].

According to the GBD results, the age group of 50-69 years incurred the highest COPD burden in Iran. From 1995 to 2015, this group approximately accounted for $33 \%$ of the number of COPD DALYs. Additionally, $28.5 \%$ of the deaths from COPD occurred in this group. The age groups $15-49$ years and $>70$ years were responsible for 28 and $27 \%$ of the number of DALYs, respectively. There are several reasons that the COPD burden mostly occurs between the ages of 15 to 70 years. First, studies have shown that the risk of death for COPD is higher in this population. For example, a study illustrated that the relative risk of mortality for the age group of 45-49 years was more than that for other groups [21]. One study by Gashaw et al. in Ethiopia showed that more than $60 \%$ of cases for COPD occurred in individuals over 30 years [22]. Secondly, part of the higher burden of COPD in this age group is due to the population structure of Iran, so that the population of 20 to 60 years in Iran has increased in recent years. Third, it may be owing to an increase in exposure to factors such as air pollution, cigarette, smoking, and occupational conditions that are more common in these groups. May et al. examined the burden of COPD in 2015. Their results

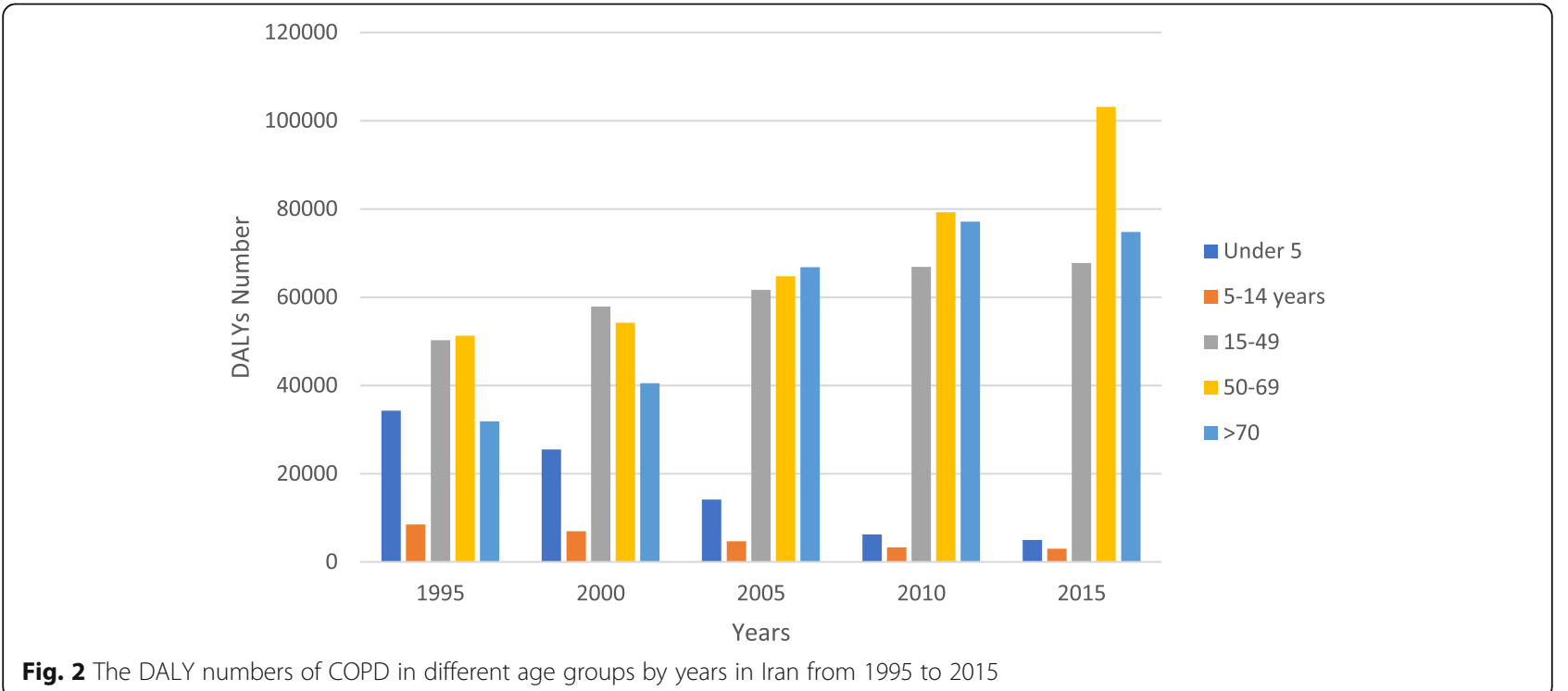

Fig. 2 The DALY numbers of COPD in different age groups by years in Iran from 1995 to 2015 
explicated that in the United States, in the last 20 years, COPD accounted for $56.7 \%$ of deaths related to lung diseases, and deaths from COPD increased, especially in females. The mortality relative risk from COPD in smokers compared to nonsmokers is 25.61 for males and 22.35 for females with mortality continuing to rise in both genders [23].

The present study clearly demonstrated that why the burden of COPD was higher in males than in females, such that the number of DALYs for males was $60 \%$ more than that for females at all ages from 1995 to 2015. Furthermore, the number of deaths for males was $67 \%$ more than that for females, which was statistically significant. Minicuci et al studied the DALYs due to COPD in northern Italy in 2011 and estimated that total DALY (per 1000) for COPD varied between 2.1 and 3.4 years among males and between 1 and 2.3 years among females [24]. A study in Finland indicated that $78 \%$ of the samples who had a symptom of COPD were males [25]. The higher burden of COPD in males can be due to several reasons. COPD occurs more frequently in males. In all years, the number of deaths among males was more than that among females. The number of deaths was 6981 and 3532 for males and females, respectively, in 2015. Moreover, the incidence and prevalence rate were higher in males than in females. Studies revealed more risk factors for COPD in males than in females [26, 27]. Part of the increased burden of COPD in males is related to population structure and demographic characteristics. In Iran, the population of males is higher than that of females, and the employment rate is higher for males.

As other studies, our results demonstrated that YLLs were the main contributor to DALYs calculations, since COPD was a mortal disease. In fact, the burden of fatal diseases had predominantly affected from premature death. The assessed DALY showed that this parameter had an increasing process from 1995 to 2015 at all ages and in both genders. In 2015 compared to 1995, there was an approximate increase of $43 \%$ in the DALYs number due to COPD. While the number of deaths at $114 \%$, the YLLs by $48 \%$, and the YLDs on $29 \%$ were increased. Moreover, these results disclose that the burden of COPD in Iran, like other countries, has raised significantly over time. Studies have estimated that COPD will become the third most common cause of death by the year 2020, leading to being an important cause of morbidity, mortality, and health-care costs worldwide [4, 28].

To the best of our knowledge, this is the first attempt assessing the burden of COPD in Iran. The morbidity and mortality indices concurrently reported that it could be a road map for health policymakers. In addition, analysis of the burden of COPD based on a trend can provide useful information to estimate the economic burden of this disease. However, this study had some limitations. The results of the GBD study do not distinguish between the results of diseases related to COPD and assess them in a category; this is highly important for policy purposes.

\section{Conclusions}

DALY represents a summary measure to improve the capacity of assessing population health needs and priorities. Policymakers owning such a further element of evaluation may be better oriented in allocating resources for COPD among the different health care chapters: prevention, emergency, chronicity, and rehabilitation. COPD is a critical public health issue in Iran and worldwide. It has had an increasing trend in recent years. The results of this study and others indicated that the majority of DALYs in COPD were due to YLLs, demonstrating that prevention and early detection should be considered, especially in the age group of 15 to 70 years.

\section{Acknowledgments \\ All authors are appreciating from Fasa University of Medical Sciences and we thank the Institute for Health Metric and evaluation (IHNE) team for providing the results of the Global Burden of Disease (GBD) studies. \\ Authors' contributions \\ AF and SYH were the principal investigators of the research and designed the study. AF and AK collected data, managed and analyzed the data. AF and VM drafted the first version of the manuscript, and all authors contributed, reviewed, and approved this paper.}

\section{Funding}

This work was supported by the Fasa University of Medical Sciences.

\section{Availability of data and materials}

The preliminary data on chronic obstructive pulmonary disease are available in the global burden of disease study.

Ethics approval and consent to participate

This paper is the result of a research approved by Fasa University of Medical Sciences. (IR.FUMS.REC.1396.292).

Consent for publication

Not applicable.

\section{Competing interests}

The authors declare that they have no competing interests.

\section{Author details}

${ }^{1}$ Fasa University of Medical Sciences, Fasa, Iran. ${ }^{2}$ Department of Public Health, Bam University of Medical Sciences, Bam, Iran., Bam University of Medical Sciences, Bam, Iran. ${ }^{3}$ Department of Health Management and Economics, School of Public Health, Urmia University of Medical Sciences, Urmia, Iran.

${ }^{4}$ School of Public Health, Fasa University of Medical Sciences, Fasa, Iran.

Received: 14 December 2019 Accepted: 30 April 2020

Published online: 25 May 2020

\section{References}

1. Bhatt SP, Soler X, Wang X, Murray S, Anzueto AR, Beaty TH, et al. Association between functional small airway disease and FEV1 decline in chronic obstructive pulmonary disease. Am J Respir Crit Care Med. 2016;194(2):17884.

2. Tsai SC. Chronic obstructive pulmonary disease and sleep related disorders. Curr Opin Pulm Med. 2017;23(2):124-8. 
3. Portegies ML, Lahousse L, Joos GF, Hofman A, Koudstaal PJ, Stricker BH, et al. Chronic obstructive pulmonary disease and the risk of stroke. The Rotterdam study. Am J Respir Crit Care Med. 2016;193(3):251-8.

4. Mannino DM, Buist AS. Global burden of COPD: risk factors, prevalence, and future trends. Lancet. 2007;370(9589):765-73.

5. Adeloye D, Basquill C, Papana A, Chan KY, Rudan I, Campbell H. An estimate of the prevalence of COPD in Africa: a systematic analysis. COPD: J Chron Obstruct Pulmon Dis. 2015;12(1):71-81.

6. Blanco I, Diego I, Bueno P, Fernández E, Casas-Maldonado F, Esquinas C, et al. Geographic distribution of chronic obstructive pulmonary disease prevalence in Africa, Asia and Australasia. Int J Tuberc Lung Dis. 2019;23(10): 1100-6.

7. Pronzato C. Chronic obstructive pulmonary disease and obstructive sleep apnea. Association, consequences and treatment. Monaldi Arch Chest Dis. 2010;73:4.

8. ur Rehman A, Ahmad Hassali MA, Muhammad SA, Shah S, Abbas S, IAB HA, et al. The economic burden of chronic obstructive pulmonary disease (COPD) in the USA, Europe, and Asia: results from a systematic review of the literature. Expert review of pharmacoeconomics \& outcomes research; 2019. p. 1-12.

9. Exuzides A, Colby C, Briggs AH, Lomas DA, Rutten-van Mölken MP, Tabberer $M$, et al. Statistical modeling of disease progression for chronic obstructive pulmonary disease using data from the ECLIPSE study. Med Decis Mak. 2017;37(4):453-68

10. Wyper GM, Grant I, Fletcher E, McCartney G, Fischbacher C, Stockton DL. How do world and European standard populations impact burden of disease studies? A case study of disability-adjusted life years (DALYS) in Scotland. Archives of Public Health. 2020;78(1):1.

11. Lopez AD, Mathers CD, Ezzati M, Jamison DT, Murray CJ. Global burden of disease and risk factors: the World Bank; 2006

12. Yang L-P, Liang S-Y, Wang X-J, Li X-J, Wu Y-L, Ma W. Burden of disease measured by disability-adjusted life years and a disease forecasting time series model of scrub typhus in Laiwu, China. PLoS Negl Trop Dis. 2015;9(1): e3420.

13. Timm C, Luther S, Jurzik L, Hamza IA, Kistemann T. Applying QMRA and DALY to assess health risks from river bathing. Int J Hyg Environ Health. 2016;219(7):681-92.

14. United Nations Population Division. World population prospects 2017. Available from: http://data.worldbank.org/indicator/SP.POP.TOTL.

15. Murray CJ, Vos T, Lozano R, Naghavi M, Flaxman AD, Michaud C, et al. Disability-adjusted life years (DALYs) for 291 diseases and injuries in 21 regions, 1990-2010: a systematic analysis for the global burden of disease study 2010. Lancet. 2012;380(9859):2197-223.

16. Lopez AD, Mathers CD. Measuring the global burden of disease and epidemiological transitions: 2002-2030. Ann Trop Med Parasitology. 2006; 100(5-6):481-99.

17. Murray CJ, Lopez AD, Jamison DT. The global burden of disease in 1990: summary results, sensitivity analysis and future directions. Bull World Health Organ. 1994;72(3):495.

18. Sassi F. Calculating QALYs and DALYs: methods and applications to fatal and non-fatal conditions. In: Handbook of disease burdens and quality of life measures. New York: Springer; 2010. p. 313-28.

19. Roth GA, Abate D, Abate KH, Abay SM, Abbafati C, Abbasi N, et al. Global, regional, and national age-sex-specific mortality for 282 causes of death in 195 countries and territories, 1980-2017: a systematic analysis for the global burden of disease study 2017. Lancet. 2018;392(10159):1736-88.

20. WHO G. WHO methods and data sources for global burden of disease estimates 2000-2011. Geneva: Department of Health Statistics and Information Systems; 2013.

21. Lopez A, Shibuya K, Rao C, Mathers C, Hansell A, Held L, et al. Chronic obstructive pulmonary disease: current burden and future projections. Eur Respir J. 2006;27(2):397-412.

22. Woldeamanuel GG, Mingude AB, Geta TG. Prevalence of chronic obstructive pulmonary disease (COPD) and its associated factors among adults in Abeshge District, Ethiopia: a cross sectional study. BMC Pulmonary Medicine. 2019;19(1):181.

23. May SM, Li JT, editors. Burden of chronic obstructive pulmonary disease: healthcare costs and beyond. Allergy and asthma proceedings. Rochester: OceanSide Publications; 2015.

24. Minicuci N, Benacchio L, Noale M, Campigotto F, Balzi D, Franzo A, et al. Chronic obstructive pulmonary disease: the disability adjusted life years in northern Italy. Minerva Med. 2011;102(1):1-14 PubMed PMID: 21317845 Epub 2011/02/15. eng.

25. Viinanen A, Lassenius MI, Toppila I, Karlsson A, Veijalainen L, IdänpäänHeikkilä JJ, et al. The burden of chronic obstructive pulmonary disease (COPD) in Finland: impact of disease severity and eosinophil count on healthcare resource utilization. Int J Chron Obstruct Pulmon Dis. 2019;14: 2409

26. Barczok M. COPD - Smoking is not the only risk factor. MMW Fortschritte der Medizin. 2019;161(13):66-8 PubMed PMID: 31313169. Epub 2019/07/18. COPD: Rauchen ist nicht der einzige Risikofaktor. ger.

27. Eby D. Most important risk factor missing from COPD score. CMAJ. 2019; 191(13):E370 PubMed PMID: 30936169. Pubmed Central PMCID: PMC6443521. Epub 2019/04/03. eng.

28. Herse F, Kiljander T, Lehtimäki L. Annual costs of chronic obstructive pulmonary disease in Finland during 1996-2006 and a prediction model for 2007-2030. NPJ Prim Care Respir Med. 2015;25(1):1-6.

\section{Publisher's Note}

Springer Nature remains neutral with regard to jurisdictional claims in published maps and institutional affiliations.
Ready to submit your research? Choose BMC and benefit from:

- fast, convenient online submission

- thorough peer review by experienced researchers in your field

- rapid publication on acceptance

- support for research data, including large and complex data types

- gold Open Access which fosters wider collaboration and increased citations

- maximum visibility for your research: over $100 \mathrm{M}$ website views per year

At $\mathrm{BMC}$, research is always in progress.

Learn more biomedcentral.com/submissions 